\title{
Debt and investment in the Keen model: a reappraisal of modelling Minsky
}

\author{
Antonin Pottier* \\ MINES ParisTech, PSL Research University, CERNA - Centre for Industrial Economics, i3 UMR CNRS, \\ Paris, France \\ Adrien Nguyen-Huu* \\ LAMETA - Montpellier Laboratory of Theoretical and Applied Economics, CNRS, INRA, SupAgro, \\ University of Montpellier, France
}

We examine to what extent the Keen model (Keen 1995) is a faithful modelling of Minsky's financial instability hypothesis. We focus on debt, money, and debt-induced crisis. We propose a clear interpretation of the debt: households lend unconsumed income to firms to finance their investments, and money creation is not necessary. We offer a detailed description of the economic collapse and analyse its causes thanks to numerical experiments. The crisis is triggered by profits squeezed by wages and not by debt overhang. We test alternative assumptions on the investors' behaviour to show that behaviour at very low profits is fundamental. We conclude that the Keen crisis has few Minskyan flavours.

Keywords: Keen model, financial crisis, Minsky, endogenous money, investment, debt

JEL codes: E12, E32, E51, C63

\section{INTRODUCTION}

Twenty years ago, Steve Keen (1995) proposed a model for Minsky's financial instability hypothesis (FIH). In addition to the famous Goodwin (1967) model, which produces endogenous cycles due to the covariation of labour share and unemployment, he allows firms to invest above current profits by borrowing money. The model possesses undeniable qualities: parsimonious in its assumptions, it exhibits a growth path that can be unbalanced. The debt that finances the irrational exuberance of firms can possibly destabilize the cycles, resulting in an economic crash.

In the aftermath of the financial and economic crisis that has plagued Western economies since 2008, Keen was hailed as one of the economists who anticipated the global financial crisis thanks to his 1995 model (Bezemer 2010; Fullbrook 2010). He himself relied on his model on many occasions to explain the global financial crisis (Keen 2009a; 2009b; 2009c; 2013a) and warn about a possible future crash (Keen 2013b). The Keen model has thus gained considerable attention, inside and outside academia. Researchers have devoted much time to elucidating its mathematical properties or adding specific extensions (Grasselli and Costa-Lima 2012; Costa-Lima et al. 2014;

* The authors are indebted to Matheus R. Grasselli and Gaël Giraud, as well as two anonymous referees, for their valuable remarks. Opinions presented here solely reflect those of the authors, and remaining errors are imputable to them only. The authors benefited from the support of the Chair Energy and Prosperity. 
Grasselli and Nguyen-Huu 2015). The considerable amount of theoretical work related to this model and the more frequent references to it make it necessary to investigate its economic content more deeply.

The latest development of the model that Steve Keen emphasized concerns money creation, which lies at the heart of his vision of macroeconomic theory. Keen (2008; 2009a) developed a dynamical system describing the mechanism of a monetary economy, which he connected to his Minsky model in Keen (2013a). The latter finally rejoins the two hobby-horses of Steve Keen: the importance of debt in explaining economic crisis and stagnation, and money creation from banks as the main channel of debt formation.

Our present goal is to assess the relevance of the Keen model in the light of those two concerns. We will review the understanding of both the original and the amended versions of the model (Keen 1995; 2013a). Following the post-Keynesian tradition, we set ourselves a delicate exercise, which consists of starting from the existing model and evaluating which narratives are compatible with it. We go back and forth between the economic channels that allegedly produce the crash and the mathematical mechanisms at work in the Keen model. We further check whether the model can support the narrative that comes along with it. This will shed new light on the Keen model, and on what it can reasonably, or preferably, tell or not.

The paper is organized as follows. In Section 2, we briefly review the construction of the Keen (1995) dynamical system, starting with the simple dynamics of the Goodwin (1967) model and ending with a brief description of the Keen (2013a) model with a money-creation mechanism. In Section 3, we show that Keen has failed so far to properly integrate endogenous money in his model. Actually, in the Keen model, debt is the counterpart of savings from other agents, mainly households, and not the money created by banks. In Section 4, we explain in great detail the dynamics of the Keen crisis, especially before the collapse. We highlight several quantitative limitations, most notably a long period of negative profits, that is crucial for the collapse to occur. In Section 5, we design numerical tests to isolate the mechanisms that produce the Keen crisis. Contraction of profits is related to wage increase and not to a rise in financial expenses. The behaviour of investment at negative or low profits is also crucial for the crisis to occur. This shows that the occurrence of the crisis is extremely sensitive to assumptions about investment behaviour in the negative profit range where no empirical evidence can guide the choice of the investment function. Section 6 concludes that our analysis firmly downplays the Minskyan features of the Keen model.

\section{THE KEEN MODEL}

\subsection{The Goodwin basis}

Goodwin (1967) originally models a closed economy, which produces a single, allpurpose good from capital and labour. Although one-good macroeconomics was heavily criticized by post-Keynesians in general and Joan Robinson in particular, it has the advantage that valuation of capital causes no difficulties, since everything is measured in physical units of the product. Goodwin's real economy can be read as a monetary economy with a constant price level.

Output is produced from capital and labour through a Leontief function at constant or full capacity:

$$
Y=\min \left\{\frac{K}{v} ; a L\right\}
$$


The economy has two kinds of agents, or classes: workers and capitalists. Capitalists own capital $K$ and earn profits $\Pi$ from it, workers sell their labour $L$ and earn wages $W$. The standard assumption in this dual-structured economy is that workers consume everything they earn and capitalists invest everything: $C=W$ and $I=\Pi$.

The crucial assumption is that the wage unit $w=W / L$ grows in relation to the employment rate $\lambda$, the ratio of employed labour $L$ to potential labour force $N$ :

$$
\frac{\dot{w}}{w}=\Phi(\lambda),
$$

with an increasing $\Phi$. This wage-bargaining curve reflects the power of workers in the negotiation of their wages: their power is higher when labour is scarce.

Introducing the wage share of production $\omega=W / Y=w / a$, the accumulation of capital and the wage-bargaining curve can be rewritten as the following system of differential equations:

$$
\left\{\begin{array}{c}
\frac{\dot{\lambda}}{\lambda}=\frac{1-\omega}{\nu}-\delta-\alpha-\beta \\
\frac{\dot{\omega}}{\omega}=\Phi(\lambda)-\alpha
\end{array},\right.
$$

where $\alpha$ is the growth rate of labour productivity, $\beta$ the population growth rate and $\delta$ the depreciation rate of capital.

Under some assumptions, this dynamical system has one equilibrium point (Grasselli and Costa-Lima 2012). Outside that point, the dynamics produce closed orbits around it, where wage cycles follow employment-output cycles, similarly to historical observations. The oscillations reflect that labour and capital need to perpetually adjust to one another because of the fixed proportion of factors in the Leontief production function. Two forces sustain them: the exogenous growth of labour productivity, and the wage dynamics (equation (2)). When capital formation is higher than the natural rate of growth of the economy (growth of productivity plus population), employment increases, which leads to a growing wage share. This reduces profits, and so capital formation, which eventually creates unemployment and decreases the wage share. This further stimulates capital formation, and the cycle goes on.

\subsection{Keen's introduction of debt}

Keen (1995) speaks no longer of capitalists and workers - this had become oldfashioned by that date - but of firms and households. He further introduces a third class of agents: the banking sector, to which firms can become indebted. If $D$ is the net debt from firms to the banking sector, firms pay financial expenses to the banking sector according to an interest rate ${ }^{1} r$. Thus profits are now equal to the surplus of production over wages, minus financial expenses: $\Pi=Y-W-r D$.

1. We follow Keen (1997) with $r$ constant. Keen (1995) assumes $r$ grows with the debt-tooutput ratio. We focus on the simpler form requiring fewer assumptions. It does not invalidate the generality of our analysis and produces equivalent complex dynamics. 
Keen's major modification lies, however, in the behaviour of firms. Instead of investing all their profits, firms now invest a proportion $\kappa$ of production that depends on the profit share $\pi=\Pi / Y$ (or, up to a constant thanks to (1), the profit rate $\Pi / K$ ):

$$
I=\kappa(\pi) Y
$$

so that $\dot{K}=\kappa(\pi) Y-\delta K$. The investment desired by firms is always realized. The function $\kappa$ can be seen as a formal representation of the animal spirits of the investors/ capitalists. Investment is paid by profits, and, if necessary, by a debt to the banking sector, which adds to the total stock of debt $D$ :

$$
I=\Pi+\dot{D}
$$

This sets the model in a stock-flow consistent framework (Grasselli and Nguyen-Huu 2015).

Accordingly, the law-of-motion of the debt-to-output ratio $d=D / Y$,

$$
\dot{d}=\kappa(\pi)-\pi-d\left(\frac{\kappa(\pi)}{\nu}-\delta\right),
$$

is added to the dynamics of (3), where the evolution of employment rate takes into account the new investment function:

$$
\frac{\dot{\lambda}}{\lambda}=\frac{\kappa(\pi)}{\nu}-\delta-\alpha-\beta .
$$

The mathematical analysis of equilibrium points and their local stability is undertaken in Grasselli and Costa-Lima (2012). Two non-trivial asymptotic equilibria bear a clear interpretation. Both are locally attractive for a wide range of parameters, and conditions on $\Phi$ and $\kappa$.

- A 'good' equilibrium generalizes the equilibrium point of the Goodwin model: the growth rate of the economy matches the natural rate of productivity of labour, the employment rate is positive and the wage share and the debt-to-output ratio constant.

- A 'bad' equilibrium is a singular attractive state, where debt-to-output is infinite while employment rate and wage share are zero. The path towards this equilibrium will be studied in depth in Section 4 .

\subsection{Extension to money creation}

Chapman and Keen (2006) and Keen (2008; 2009a; 2010) modelled the mechanism of money creation from banks, taking inspiration from Graziani (2003) circuit theory. It is based on a double accounting description of loans from banks to firms. For that purpose, different accounts are introduced: a bank vault $B_{T}$, which stores the bank notes, a bank transfer account $B_{T}$, through which transactions are made and where financial revenues accumulate, a household deposit $H_{D}$, a firm deposit $F_{D}$ and a firm loan ledger $F_{L}$, which record the amount of debt of the private sector to the bank. Transactions between agents, lending, borrowing and paying interest are all accounted for with double-entry book-keeping. Spending behaviour of households and bankers is assumed 
to be proportional to their wealth. The sum of the transactions on each account gives the net variation of the account, which results in five differential equations.

Keen (2013a) connects this model of monetary flows to the above real economy. This coupling is realized thanks to three links:

1. Investment of firms is totally funded by borrowing money from banks, that is, endogenous money creation is equal to the nominal investment.

2. Financial expenses $(r D)$ of the Keen model are replaced by financial expenses on debt $r_{L} F_{D}$ minus financial revenues from firm deposits $\left(r_{D} F_{D}\right)$. If interest rates on debt and deposits are equal, this is simply the financial expenses of net debt $\left(F_{L}-F_{D}\right)$, as in the Keen model.

3. The nominal and real spheres are related thanks to a price level that relaxes towards a mark-up over monetary cost of production.

This coupling purportedly provides an explicit representation of the financial counterparts of the physical production of the Keen model. The next section discusses the role of money creation in the Keen model and the meaning of debt, and will investigate whether the coupling of the financial sphere and the real production achieves the full integration that is claimed.

\section{DEBT AND MONEY IN THE KEEN MODEL}

Keen emphasizes the role of banks and money creation as the key ingredients of his model to produce the debt crisis instability (Keen 2013a, sec. 6). Because Keen presents his model with his views on endogenous money, debt and money creation are somehow conflated. Our aim is first to make clear what debt actually represents in the Keen model, and, second, to delineate the role of banks and money creation in it.

\subsection{Initial versus final finance}

Debt is simply introduced in Keen (2013a, p. 225) by the description that 'a banking sector ... finances the gap between desired investment and actual profit ... by a change in the level of debt', which leads to equation (5). As Lavoie (2014, p. 325) recalls, following Graziani (1990), finance can have two different meanings: initial finance, that is, 'the bank deposits needed to make a transaction', or final finance, that is, 'saving as defined by the national accounts'.

In line with Keen's emphasis on banks and money creation, one gets, from reading Keen (1995) or Keen (2013a), the feeling that new debt $\dot{D}$ in the Keen model represents initial finance. In that case, new debt $\dot{D}$ would be the nominal amount of money created by banks at each time, in an endogenous response to firms' desire to invest. However, this is not compatible with the equations of the Keen model.

First, note that quantities of the Keen model are labelled in real terms (measured in physical units of the final good), or, equivalently, in nominal terms with a constant price, and that desired investment $I$ is also actual investment (see the accumulation equation). Because actual investment is at most equal to total output, a fixed quantity, the new debt, which is actual investment minus actual profit, is also bounded. However, initial finance in nominal terms is not bounded, for banks can print whatever quantities of money they wish. If banks printed more money than the current value of output, what would happen is a price increase, so that the nominal purchasing power should 
match productive capacity of the economy. The Keen model has no such correction mechanism. This is our first hint that new debt $\dot{D}$ cannot represent initial finance.

Second, consider the following accounting equations. In the income approach, output is divided according to the revenues of agents $Y=W+r D+\Pi$, whereas in the expenditures approach, it is divided according to its final use, that is, consumption or investment: $Y=C+I$. Now, new debt is the difference between investment and profits, $\dot{D}=I-\Pi$. Combined with the two previous, we arrive at:

$$
W+r D=C+\dot{D} .
$$

Here, new debt appears as the part of households' and bankers' revenues that is not consumed, that is, saved. This should tell us that new debt $\dot{D}$ represents final finance in real terms, that is, savings from some agents (households and banks) that are the counterparts of firms' liabilities.

The full model of Keen (2013a), with bank accounts added to the equations for real quantities of the Keen model, as explained in Section 2.3, seeks to overcome these shortcomings and to provide an exhaustive description of the finance circuit while preserving the insights of the Keen (1995) model. There, it is made clear that new debt from firms represents initial finance provided by bank money creation.

The full model of Keen (2013a) suffers from a grave deficiency: it is NOT stockflow consistent. Indeed, consumption in the monetary sphere is in no way related to consumption in the real sphere. The former is given by spending patterns from deposit accounts, the latter is what is left from output once investment has been made, and the two don't match. ${ }^{2}$ As a consequence, some earned profits in the real sphere do not correspond to any transaction in the monetary sphere, whereas some spending transactions in the monetary sphere buy nothing at all in the real sphere. This should be no surprise since there is no mechanism to reconcile consumption and investment plans, expressed by spending and investing behaviours, so that they add up to total output.

So, we can put aside this inconsistent coupling of the monetary and real spheres, and focus on the monetary sphere, which is stock-flow consistent by design. Then, variation of the net debt of firms (firm loan ledger $F_{L}$ minus firm deposit $F_{D}$ ) is equal to variation of the other deposits (household $H_{D}$ and bank $B_{T}$ ): $\dot{B}_{T}+\dot{H}_{D}=\dot{F}_{L}-\dot{F}_{D}$. Here again, new net debt of firms has an increase in deposits of the other agents of the economy as a counterpart. The spending of money created to finance investment causes an equal amount of money to accumulate as bank deposits.

This reinforces our conclusion: the flow of new debt from the firm sector is not the nominal amount of money created by banks to (initially) finance investment, but it is the real amount of saving from agents that (finally) finance investment.

\subsection{Endogenous money creation vs loanable funds}

Now that we have settled the meaning of debt in the Keen model, we can move to the importance of money creation in it. There are mainly two paradigms on money and credit, internal heterogeneity notwithstanding: the loanable funds (LF) paradigm, 2. Mathematically, with the notations of Keen (2013a), $\frac{B_{T}}{\tau_{T}}+\frac{H_{D}}{\tau_{H}}$ and $Y .\left(1-\operatorname{Inv}\left(\pi_{r}\right)\right)$ should
be equal, which is not the case. 
where deposits make credits and the supply of money is exogenous, and the endogenous money creation (EMC) paradigm, where credits make deposits and the supply of money is demand-led.

The Keen model is an economic model in real terms, as no variables, especially the debt, can be endowed with a truly nominal meaning. As such, the Keen model is $a$ priori agnostic in the face of the two paradigms. ${ }^{3}$ It is compatible with these two opposite paradigms in the same sense that the Goodwin model or the Solow growth model are. As real models that make no assumption on financial transactions, any monetary phenomenon is foreign to their structure. They are thus compatible in principle with any kind of monetary paradigm because they are silent on this part of economic life.

We however question that the Keen model can convincingly endorse the EMC paradigm. The columns of this journal have hosted a hot debate about aggregate effective demand and endogenous money, launched by a contribution from Keen (2014), with comments from Fiebiger (2014), Lavoie (2014), Palley (2014) and Reissl (2016), and a reply from Keen (2015). What is important for our purpose is that, despite their points of contention, all participants agree that endogenous money has an impact on aggregate demand: whereas Keen supports a kind of post-Keynesian monetarism (Palley 2014), others, for example, point to shifting purchasing power between agents with different propensity to spend. Different channels, but a common impact on aggregate demand.

Consider however that in the Keen model, as stated in equation (1), total output $Y$ is fixed by the current capital stock, operated at full capacity. Aggregate demand is always equal to potential aggregate supply, which is the result of past accumulation of capital. Revenues of workers and bankers are also historically determined, so that distribution of revenues is completely fixed. If there is any endogenous money in this model, it solely impacts the level of investment but consumption will compensate exactly so that the total output does not change at all.

Endogenous money in the Keen model impacts only the final use of the output (consumption or investment), not the distribution of revenues or the level of aggregate demand. Keen himself would relate this feature to an underlying loanable-funds structure, as he said: 'The change in debt is ignored in Loanable Funds for the legitimate reason that, in that model, the debt-financed increase in spending power by the borrower is largely offset by a diminished spending power for the lender' (Keen 2015, p. 607) which is the very situation in the model. For the Keen model to account for endogenous money creation, one needs to uncouple output $Y$ and aggregate supply, via flexible capacity utilization, inventories, or by considering an open economy. In opposition to what Keen (2014) states, money creation cannot be the single source of change of aggregate demand, but aggregate demand shall be sufficiently flexible in order to include consistently the effect of money creation.

The Keen model has thus more features echoing the LF paradigm than the EMC. In this respect, the following narrative, with only two agents (households and firms), and a direct credit relation between the two, makes the suitability of the Keen model to LF quite explicit. Revenues of households are $W+r D$, whereas revenues of firms are $\Pi$. Firms want to invest $I$, with the same investment function as above, and borrow from households the amount of investment that is above their profits. Thus debt is accrued by the amount $\dot{D}=I-\Pi$. This represents the savings of households, which consume the remaining part of their income.

3. We thank Matheus R. Grasselli for stressing this point. 
This relationship between debtors and creditors dispenses itself of the banking system but it leads exactly to the aggregate dynamics of the Keen model. What is particular in this version is that households do not choose their savings. Instead, they adjust them so that firms can invest what they want. Note that we do not take the stand that the LF story is realistic (it is certainly not), simply that it is compatible with the basic macroeconomic structure of the Keen model.

The emphasis of the role of banks and endogenous money in the Keen model is thus misleading. It conceals that the very macroeconomic structure imposes some sort of household savings, that is the counterpart of firms' debt. Moreover, the Keen model is too strongly compatible with the LF paradigm to accurately endorse the EMC. The LF narrative that we have outlined proves that neither banks nor endogenous money are necessary to have the dynamics of the Keen model.

\section{THE KEEN CRISIS}

Having clarified the meaning of debt and the role of banks in the model, the next step is to understand how their interplay produces a crisis. What is called crisis or crash is the convergence towards the 'bad' singular equilibrium, a path along which wages and employment dwindle to zero and debt-to-output grows to infinity. Keen (1995) and subsequent papers labelled it the Minsky crisis, but we prefer the term Keen crisis as this article highlights the discrepancy between Minsky's FIH and the crisis exhibited by the Keen model.

\subsection{Qualitative features}

This crash is illustrated by Figures 1 and 2 for one starting point. ${ }^{4}$ For a while, the wage share and employment oscillate in a fashion similar to the Goodwin model. Cycles amplify until an unsustainable threshold is reached, after which wages and employment collapse to zero.

We explain below in a literary manner the sequence of economic events that constitutes the Keen crisis and emphasize the causal mechanisms behind the dynamics. To expose the economic insights, we have identified four economic periods separated by three crucial moments.

\section{From contraction to expansion}

On a background of business cycles à la Goodwin, the share of financial expenses in the output distribution grows slightly but steadily. Around the times 110-120, the economy is in a recession; employment declines towards a minimum. The wage share is quickly decreasing due to a low employment rate (below 35 per cent). Symmetrically, profits rise, mostly due to wage reduction because the decline of financial expenses is modest. Moment 1 is reached: investment euphoria begins.

4. Simulations with various initial points in the basin of attraction of the bad equilibrium present the same phenomena. Parameters and specific functions are taken from Keen (2013a). Providing the conditions for convergence to the bad equilibrium hold true, the shapes of the investment function $\kappa$ and the wage bargaining function $\Phi$ mainly influence the local qualitative shapes of trajectories, but do not invalidate the generality of the description we make hereafter. 


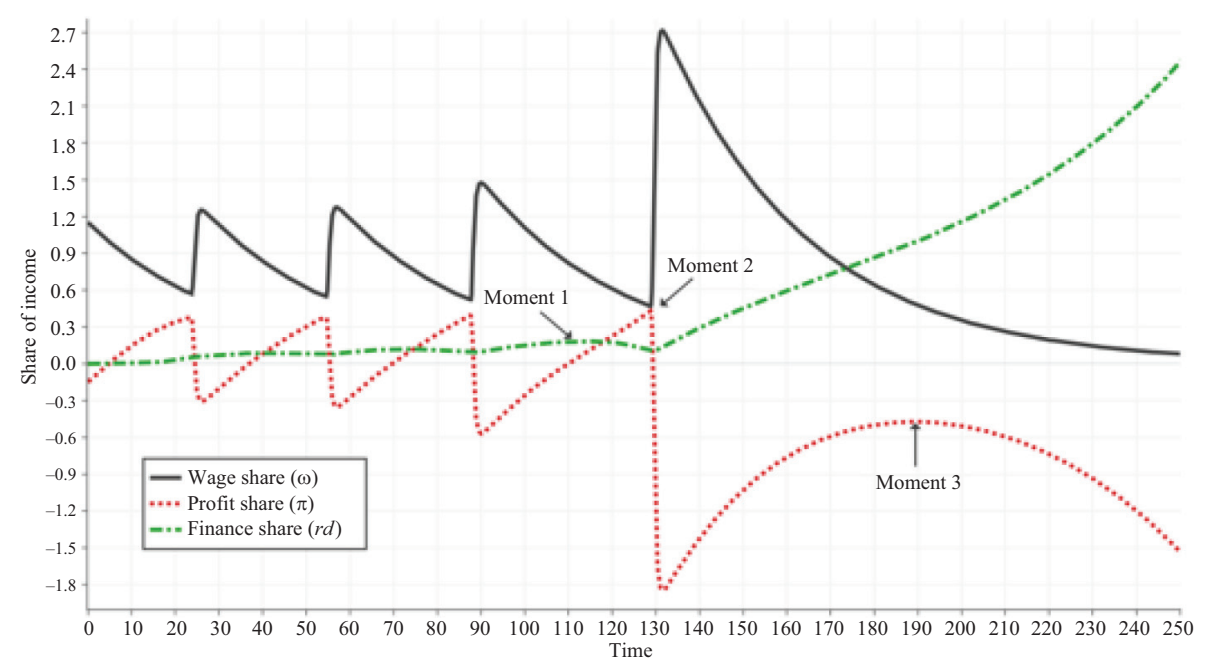

Source: Parameters taken from Keen (2013a) and $r=0.03$.

Figure 1 Keen model: dynamic paths of shares of incomes (wages, finance and profits)

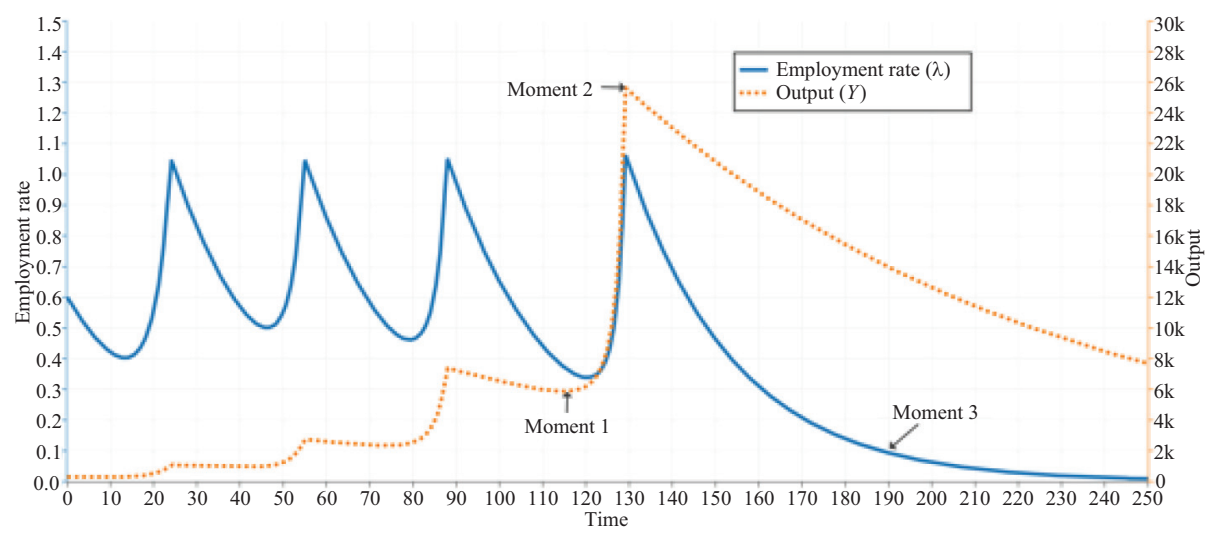

Note: Parameters as in Figure 1.

Figure 2 Keen model: dynamic paths of employment $(\lambda)$ and output $(\mathrm{Y})$

\section{Bubble fuelling}

After Moment 1 , the profit share $\pi$ increases and the investment $\kappa(\pi)$ skyrockets to unprecedented levels. Debt emission takes over to sustain capital accumulation at a fast pace. Output grows, creating a turning point in employment, which reaches full labour force..$^{5}$ This in turn pushes wages up through the roof $(\omega \geq 2.7)$. Wages crush

5. The wage-bargaining function $\Phi$ in Keen (2013a) allows for $\lambda>1$. See Grasselli and Costa-Lima (2012) for a function forbidding that situation. 
profits very rapidly to harsh negative values $(\pi \leq-1.8)$. This ultimate point, around time 130 in Figures 1 and 2, defines Moment 2: the utmost financial fragility of firms.

\section{Bubble burst}

This is the no-return crisis moment from time 130 to time 190. Profits are negative and firms stop investing or even disinvest. Consequently, capital depreciates or is destroyed, output decreases and unemployment increases. Wages are reduced slowly. In parallel, firms still get indebted, not to invest but in order to pay wages and financial expenses. Debt-to-output ratio grows exponentially due to the growth of nominal debt and the contraction of output. From wage depression, the profit share increases, yet remains negative. It reaches a local maximum at Moment 3 (time 190).

\section{Collapse}

After Moment 3, the wage share and the employment rate continue to decrease steadily. The partial recovery of the profit share (which, however, stays negative) is dampened by the increase in financial expenses. At this moment, wage reduction is not enough to compensate for interest on debt, nor reduce the overall level of debt. Firms are bound to increase their debt just to pay wages and interest. Debt continues to rise, capital and output dwindle and profits fall further.

\subsection{Quantitative limitations}

In the Keen crisis, the values taken by state variables are strikingly unrealistic: for example, the wage share is above unit (even above two), profit share is negative, and investment reaches more than 30000 times the output level ...

When assessing this quantitative inadequacy, two remarks should be kept in mind: first, variables of the model are instant values in continuous time, whereas only average values over a period (a quarter or a year) are empirically estimated (notably for the wage share or the employment rate which are flow variables). Second, the lessons of the model are learned more from the stylized dynamics than the exact values of the variables.

Nevertheless, the disparity between mathematical variables and real values must be limited. Logical bounds should still prevail: investment cannot exceed output, consumption cannot be negative. Reasonable values are expected for arguments of the wage-bargaining $(\Phi)$ and investment $(\kappa)$ functions, in order to keep the economical meaning of the model.

Whereas various specifications of the Keen model allow the employment rate $\lambda$ or the investment share $\kappa(\pi)$ to be kept below one (Grasselli and Costa-Lima 2012; Costa-Lima et al. 2014), these do not remove all the oddities of the Keen model. In particular, from our numerical tests, profits systematically reach negative values, at least around Moment 2, and more generally as soon as wages are high enough. This unrealistic feature is common to Keen (1995) and further specifications because there is no feedback mechanism that bounds the wage share, which often goes over one, thus crushing profits to negative values.

Let us pause to investigate the relevance of negative profits to understand the Keen crisis. When profits are negative, production does not cover wages and financial 
expenses. If firms get indebted at this point, borrowed money is used to pay for current expenses. We have the strange situation where creditors lend money to firms so that they pay back their financial fees on existing loans. If this may happen temporarily (when it is a liquidity problem), it does not make economic sense to sustain such a situation for too long. At some point, it becomes just a play in book-keeping. Interests on existing debt are met with new debt, artificially postponing the bankruptcy that is necessary because firms are no longer solvent.

In the Keen crisis, firms have negative profits and use debt to meet their current financial obligations from Moment 2. The convergence to the 'bad' equilibrium is thus an artifact of modelling: what would happen in reality would be an overall bankruptcy. ${ }^{6}$ Sometime after Moment 2, the simulation ceases to be meaningful, for an unmodelled event (the bankruptcy) would deeply change the dynamics. ${ }^{7}$

The simulation certainly does not make much sense after Moment 3: at this point, negative profits have been lasting for longer than the typical business period (60 time units from Moment 2 to Moment 3, to be compared to a business period around 40 time units). Despite the impressive richness of the Keen crisis, any relation to a meaningful narrative must cease at last at Moment 3: our attention should focus on what happens between Moments 2 and 3.

\section{NUMERICAL DISSECTION OF THE KEEN CRISIS}

One intuition emerges from the previous discussion: negative profits are crucial in initiating the crash. In this section, we design numerical experiments to explore this intuition more deeply, especially the importance of wages (and not of financial expenses) to generate negative profits and the relevance of the investment function.

\subsection{The overlooked importance of wages}

The smooth increase in financial expenses before the crisis occurs (see Figure 1) might support a connection between the Keen crisis and the level of debt. This link however needs to be qualified and pinpointed, beyond a general feeling that debt matters. This is our aim in this sub-section.

We have suggested that a tremendous wage increase before Moment 2 crushes profits to negative values and is fundamental to producing the Keen crisis. To compare ceteris paribus the importance of wages and debt in affecting the financial fragility of firms, we take the economic path of Figure 2 as a baseline scenario, and shock wages and debt separately at Moment 2: each variable undergoes a 25 per cent, 35 per cent or 45 per cent reduction, which brings an equivalent reduction in wage share and financial expenses respectively. All these shocks can be seen as negotiated

6. According to the previous section, creditors are workers, so that bankruptcy would mean that ownership is transferred from capitalists to workers, a narrative coherent with the fact that very high wages make it possible for workers to accumulate claims on capitalists (see below). This quiet expropriation of capitalists by workers thanks to the mechanisms of the market economy surprisingly makes Keen an unwitting follower of Samuelson and Modigliani (1966) and Sato (1966) with their anti-Pasinetti (1962) theorem.

7. In an overlooked footnote, Keen (1995, p. 614) himself warned that the model should not be taken too seriously when it approaches collapse. 
decisions (wage decrease, partial debt relief) between the actors of the economy for fear of the impending crisis. The results are displayed in Figure 3.

They show that a substantial decrease in the debt, at the moment of utmost financial fragility, does not prevent the crisis and does not even alter the economic path. On the contrary, equivalent shocks on wages significantly postpone the crash and add one business cycle before it, thus having a much more important impact in the model dynamics at this moment than the debt level. Only a debt reduction of at least 90 per cent can revive the economy for one cycle respite before the collapse.

Behind these results is the fact that profits are pushed up indifferently by a shock on wages or debt, so that the absolute size of the shock matters. This strengthens the importance of the wage share, which varies considerably in the course of the Goodwin cycle at the core of the Keen model. Indeed, wage share is multipled by five from Moment 1 to Moment 2, from 0.5 to 2.5 , whereas the share of financial expenses actually decreases, from 0.17 to 0.1 . As wage variations are one order of magnitude larger than variations of financial expenses, wages drive variations of profits and wage increases are in the Keen model primarily responsible for the financial fragility of firms.

We do not say that financial expenses play no role in the crisis: assuming $r=0$ to exempt the firm from paying interest makes employment and the wage share no longer dependent on the debt level, and the model cannot produce the Keen crisis. Financial expenses are necessary from a causal point of view, but they come into play at the very end of the Keen crisis, around Moment 3.

A test, similar to the previous one, will confirm the conclusion. Wages and debt are again shocked downwards, but at Moment 3 instead of Moment 2. As Figure 4 shows, only a 45 per cent shock on the debt has a significant impact on the system. Figure 1 helps in predicting this outcome: at Moment 3, financial expenses are greater than the wage share, as is the impact of shocks on this variable, whereas the contrary was true at Moment 2.

Financial expenses are only the second force, after wages, that put pressure on profits, a pressure which generates the crisis before Moment 3. They are therefore of

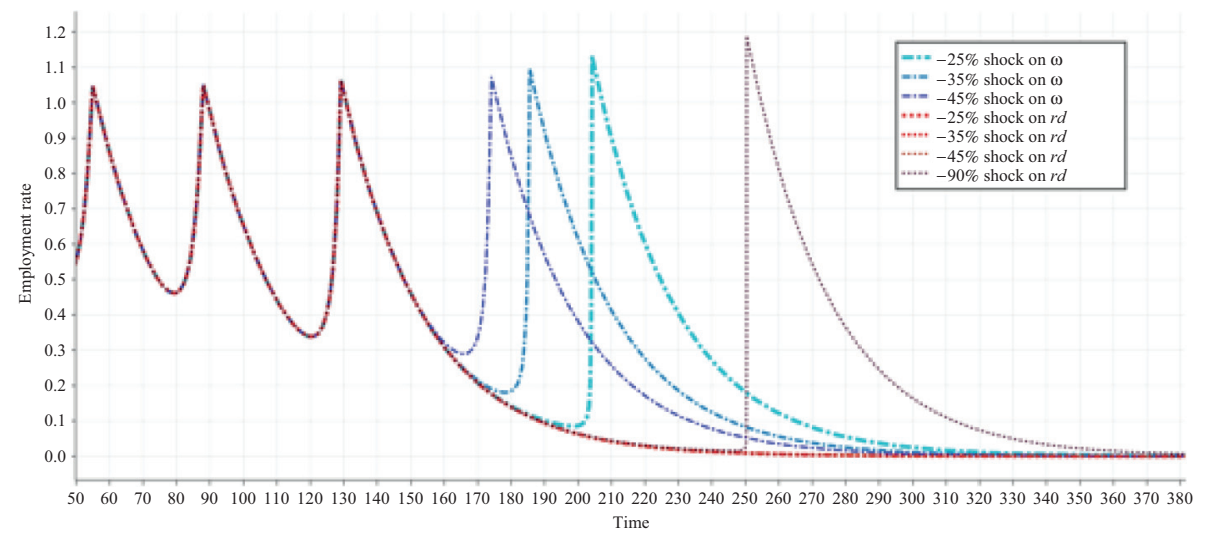

Note: Parameters as in Figure 1.

Figure 3 Testing the importance of wages or debt: dynamic path of employment rate with shocks at Moment 2 


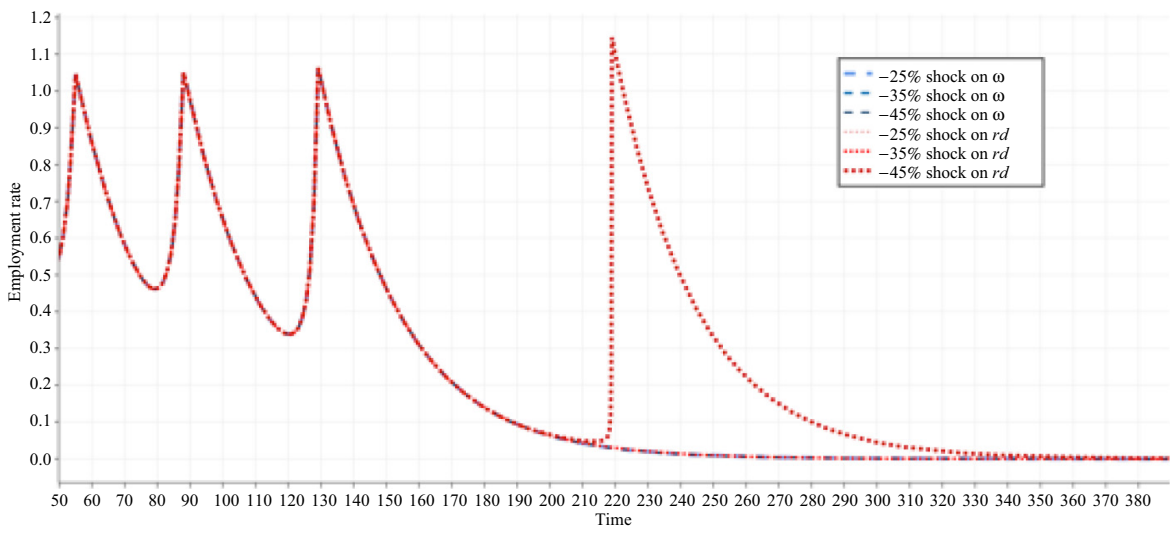

Note: Parameters as in Figure 1.

Figure 4 Testing the importance of wages or debt: dynamic path of employment rate with shocks at Moment 3

limited importance for the Keen crisis when the simulated economic path still makes sense. They only play a role at the end of the crisis around Moment 3, after an increase in debt-to-output ratio that occurs after Moment 2. This points to the role of the investment function after this point, to which we now turn.

\subsection{The puzzling significance of the investment function at negative profits}

The marked increase of debt share from Moment 2 to Moment 3 happens when profits are negative. In this period, firms get indebted because there is a persistent gap between their expenditures and their earnings. Actually, because both are negative, firms do not disinvest enough to cover their negative profits: they have to run into new debt. Such a situation, which combines negative profits and indebtness, is essential for the Keen crisis. ${ }^{8}$ But, as said above, it has little economic sense, as it amounts to an ever-postponed bankruptcy. This suggests that a modified investment function may lead to a completely different outcome.

To test how the Keen crisis is sensitive to investment at negative profits, we run the model with an investment function where strong disinvestment replaces modest disinvestment at negative profits. ${ }^{9}$ Disinvestment will produce a contraction of the economy, but it will also partially reimburse debt, so that debt will conceivably be stabilized this way. One can see this harsh disinvestment as a way to model the bankruptcy that would occur at negative profits. Indeed, bankruptcy means that ownership of firms is transferred from debtors to creditors and this almost inevitably destroys capital, if not physical then at least intangible capital.

8. It is the very meaning of the sufficient condition for local stability of the bad equilibrium, which reads $\frac{\lim _{-\infty} \kappa}{\nu}-\delta<r$.

9. More precisely for $\pi \leq 0.04: \kappa(\pi)=2.2(\pi-0.04)+100(\pi-0.04)^{3}$; and for $\pi \geq 0.04$ : $\kappa(\pi)=0.1\left(\frac{1.1}{0.1+2.47^{\frac{-\pi+0.04}{0.11}}}-1\right)$. Parameters are almost the same as in Figure 1, and the function $\Phi$ is modified but those are minor adjustments to obtain a fast convergence towards the cycle. 
This possible justification is not a claim that the proposed function is more valid than the one Keen used. Our point is simply that this investment function is not absurd and that its dynamical consequences are worthwile investigating. We only ask the reader for a suspension of disbelief, for the sake of the experiment, no greater than the suspension of disbelief on sustained negative (aggregate) profits that is required to let the Keen crisis run its full course.

Figure 5 displays a simulation with this investment function. The distinctive feature of the Keen model, that is, the collapse in the Keen crisis, has disappeared. Asymptotic convergence towards the bad equilibrium has been replaced by limit cycles. ${ }^{10}$

The collapse at the end of the Keen crisis is highly sensitive to the specifications of the investment function at negative profits: the very symbol of the Keen model is not a robust feature. Any conclusion built on the existence of the collapse should thus be taken with caution.

The real problem comes from the fact that collapse depends so heavily on specifications of the investment function in a domain where it is not known and will never be. Indeed, only profit shares between 20 per cent and 40 per cent are known in historical records. Extrapolating the behaviour of the investment from these data to lower profits up to negative values demands a huge leap. Empirical data provide no guidance to calibrate the investment function, nor do they offer the slightest hint on economic behaviour when profit share becomes so low. This reinforces our claim that sustained negative aggregate profits is so exceptional a situation that any interpretation of the Keen model must cease afterwards.

To confirm the importance of the investment function at low profits, we perform several additional numerical tests. We do not give all the details of modifications and resulting simulations ${ }^{11}$ but simply the insights gained from these experiments.

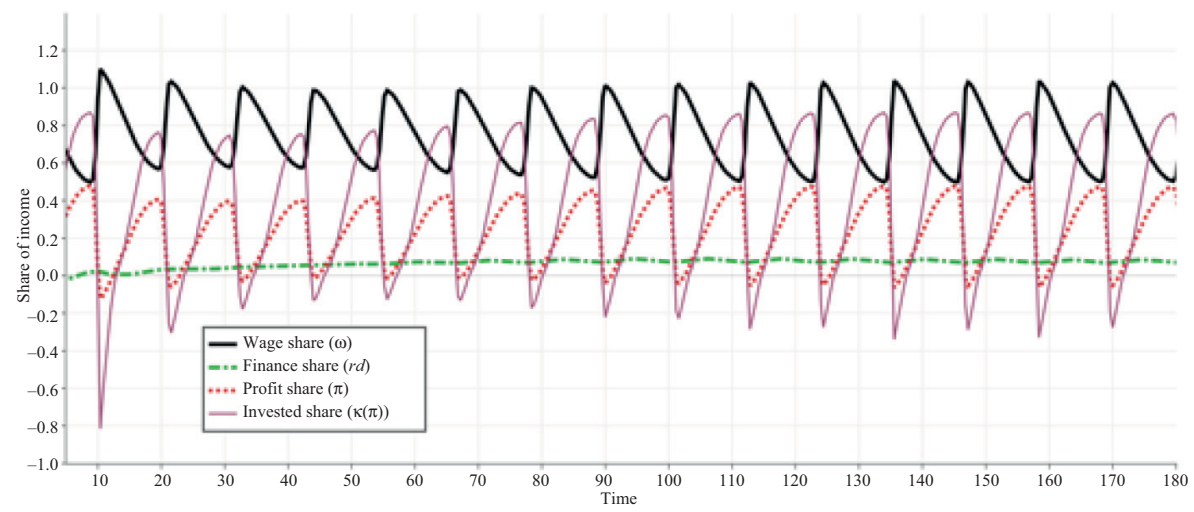

Figure 5 Keen model with disinvestment: dynamic paths converging to a limit cycle

10. Note that the sufficient condition for local stability of the bad equilibrium is no longer satisfied, but we could easily modify the investment function in the vicinity of minus infinity to have it back and still keep the limit cycles. Points inside the basin of attraction of the (locally attractive) good equilibrium still converge towards it.

11. More information is available on request. 


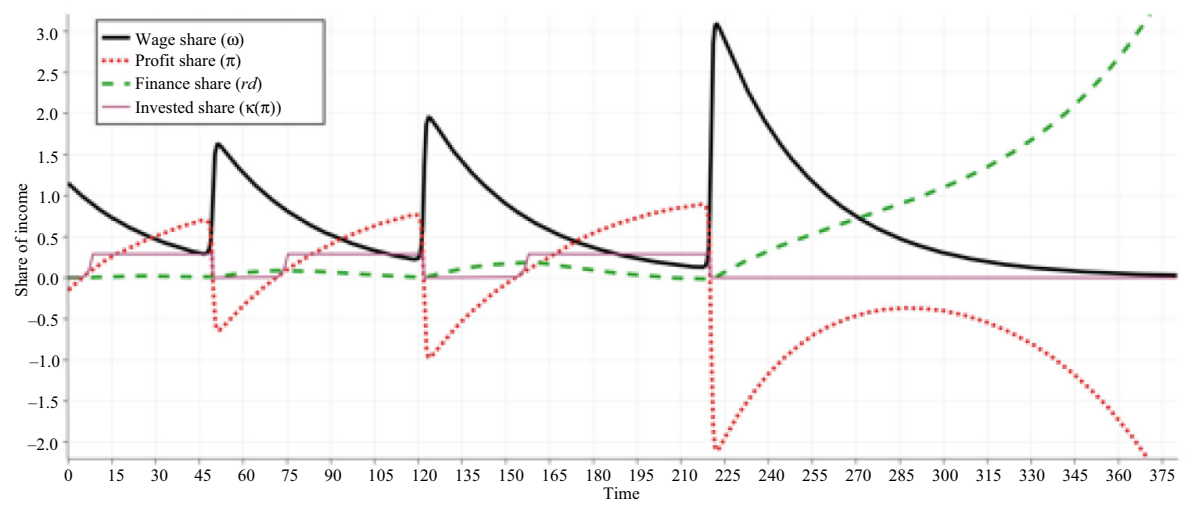

Figure 6 Keen model with capped investment: dynamic paths still leading to a crisis

In these simulations, we do not touch the investment function around the 'good' and the 'bad' equilibria, so that conditions for local stability are still met. In this case, modifying the investment function cannot change the existence of the equilibria but affects the shape of convergent dynamics and the size of their basin of attraction. When we introduce disinvestment at low and negative profits, the Keen crisis is very hard to obtain. In fact, it is almost impossible to obtain with realistic initial values. The basin of attraction of the 'bad' equilibrium has shrunk considerably. This corroborates our previous finding, that the lower part of the investment function is essential for the Keen crisis.

What is more striking is that the upper part of the investment function plays almost no role in the crisis. Indeed we capped the investment function after the 'good' equilibrium, that is, for profits a little higher than the profits of the equilibrium point, the investment is constant. To suppress the euphoria for high profits and have an excessively prudent investing behaviour instead does not impede ${ }^{12}$ the Keen crisis from happening, as Figure 6 shows.

This says that the euphoric behaviour of investors is not at all necessary to the Keen crisis. It is simply because the key mechanism we have previously uncovered is still at play. Even modest investment is sufficient to have a long boom that will drive up employment and wages, thus crushing profits into negative values, where the assumed investment function will build up debt and finally push the economy to collapse. Debt plays a minor role: indeed debt is almost null at Moment 2 of this simulation (around 220). At the core of the Keen crisis are wage increases that squeeze profits and investment behaviour at negative profits.

\section{CONCLUSION: THE RELATION TO MINSKY'S FINANCIAL INSTABILITY HYPOTHESIS}

To conclude this article, we look back at the original intentions of Keen, that is, to design a mathematical model of Minsky's financial instability hypothesis (FIH)

12. This increases the basin of attraction of the good equilibrium, but the Keen crisis is still possible for reasonable initial values. 
(Minsky 1982b, pp. 59-70; 1982a). If it is certainly difficult to obtain an exhaustive mathematical description of Minsky's FIH, differences between the FIH and the Keen crisis are too numerous to go unnoticed.

Minsky describes the evolution from financial stability to instability by examining three successive key types of (aggregative) agent behaviours: conservative banking, hedge banking and speculative banking. They relate to the economy under three respective regimes: the conservative economy, the euphoric economy (Minsky 1982b, pp. 120-124) and the presence of Ponzi financiers (Minsky 1982b, pp. 70 and 115). This evolution is cyclical, and financial cycles 'are an integral part of the process that generates business cycles' (Minsky 1974), ending eventually with a crash (Minsky 1982a). The crash is due to the Ponzi speculator when his weight is critical in the economy. Using leverage on debt facilities, he ensures past liabilities with asset returns. But in recession periods, and if the debt level is too high, low returns push him to liquidate assets to fulfil his obligations. This generates a liquidity crisis and a panic in a Fisher debt-deflation mechanism.

The Keen (1995) model has no price and no assets market, so it does not represent that aspect: no deflation trap or default risk is modelled. The same investment function $\kappa$ supposedly describes varying (financial) expectations across the three successive regimes of the economy: only the level of overall profits modifies the investment function in the Keen model, whereas changing attitude towards risk, rising expectations, revaluation of asset prices and liquidity preference all come into play in Minsky's FIH.

The simple structure of the Keen model with few variables involved (debt, employment and wage share) makes its Minskyan flavour tenuous. This is all the truer when we look precisely, as we have done here, at the instability of the Keen model, the instability that generates the Keen crisis. It is primarily caused by business cycles: high wages at the peak of the cycle are responsible for the fragility of firms. Moreover, the irrational exuberance of investors in the boom has little to do with the crisis which, on the contrary, depends on how they behave in dire times, when profits are negative. Banks can be disposed of and the role of financial expenses is minor. This is very far from Minsky. That the Keen model is very schematic is a strength for broadcasting its results, but it is also a weakness when it comes to relating its narrative to Minsky's FIH.

\section{REFERENCES}

Bezemer, D.J. (2010), 'Understanding financial crisis through accounting models', Accounting, Organizations and Society, 35(7), 676-688.

Chapman, B. and S. Keen (2006), 'Hic Rhodus, Hic Salta! Profit in a dynamic model of the Monetary Circuit', Storia del Pensiero Economico: Nuovo Serie, (2), 137-154.

Costa-Lima, B., M.R. Grasselli, X.-S. Wang and J. Wu (2014), 'Destabilizing a stable crisis: employment persistence and government intervention in macroeconomics', Structural Change and Economic Dynamics, 30, 30-51.

Fiebiger, B. (2014), 'Bank credit, financial intermediation and the distribution of national income all matter to macroeconomics', Review of Keynesian Economics, 2(3), 292-311.

Fullbrook, E. (2010), 'Keen, Roubini and Baker win Revere Award for economics', Real World Economics Review Blog, available at: https://rwer.wordpress.com/2010/05/13/keen-roubiniand-baker-win-revere-award-for-economics-2/.

Goodwin, R.M. (1967), 'A growth cycle', in C.H. Feinstein (ed.), Socialism, Capitalism and Economic Growth: Essays Presented to Maurice Dobb, London: Cambridge University Press, pp. 54-58. 
Grasselli, M.R. and B. Costa-Lima (2012), 'An analysis of the Keen model for credit expansion, asset price bubbles and financial fragility', Mathematics and Financial Economics, 6(3), 191-210.

Grasselli, M.R. and A. Nguyen-Huu (2015), 'Inflation and speculation in a dynamic macroeconomic model', Journal of Risk and Financial Management, 8(3), 285-310.

Graziani, A. (1990), 'The theory of the monetary circuit', Economies et Sociétés, 24(7), 7-36.

Graziani, A. (2003), The Monetary Theory of Production, Cambridge, UK: Cambridge University Press.

Keen, S. (1995), 'Finance and economic breakdown: modeling Minsky's "financial instability hypothesis"', Journal of Post Keynesian Economics, 17(4), 607-635.

Keen, S. (1997), 'From stochastics to complexity in models of economic instability', Nonlinear Dynamics, Psychology, and Life Sciences, 1(2), 151-172.

Keen, S. (2008), 'Keynes's "revolving fund of finance" and transactions in the circuit', in L.R. Wray and M. Forstater (ed.), Keynes and Macroeconomics after 70 Years: Critical Assessments of The General Theory, Cheltenham, UK and Northampton, MA: Edward Elgar, pp. 259-278.

Keen, S. (2009a), 'Bailing out the Titanic with a thimble', Economic Analysis and Policy, 39(1), 3-24.

Keen, S. (2009b), 'The dynamics of the monetary circuit', in S. Rossi and J.-F. Ponsot (eds), The Political Economy of Monetary Circuits, Basingstoke, UK: Palgrave Macmillan, pp. 161-187.

Keen, S. (2009c), 'Household debt: the final stage in an artificially extended Ponzi bubble', Australian Economic Review, 42(3), 347-357.

Keen, S. (2010), 'Solving the paradox of monetary profits', Economics: The Open-Access, Open-Assessment E-Journal, 4(31).

Keen, S. (2013a), 'A monetary Minsky model of the Great Moderation and the Great Recession', Journal of Economic Behavior \& Organization, 86, 221-235.

Keen, S. (2013b), 'Predicting the global financial crisis: Post-Keynesian macroeconomics', Economic Record, 89(285), 228-254.

Keen, S. (2014), 'Endogenous money and effective demand', Review of Keynesian Economics, 2(3), 271-291.

Keen, S. (2015), 'The macroeconomics of endogenous money: response to Fiebiger, Palley and Lavoie', Review of Keynesian Economics, 3(4), 602-611.

Lavoie, M. (2014), 'A comment on "Endogenous money and effective demand": a revolution or a step backwards?', Review of Keynesian Economics, 2(3), 321-332.

Minsky, H.P. (1974), 'Our financial system is fragile', Ocala Star-Banner, 15 September, p. 5A.

Minsky, H.P. (1982a), Can 'It' Happen Again?: Essays on Instability and Finance, New York: M.E. Sharpe.

Minsky, H.P. (1982b), Inflation, Recession and Economic Policy, Brighton, UK: Wheatsheaf Books.

Palley, T.I. (2014), 'Aggregate demand, endogenous money, and debt: a Keynesian critique of Keen and an alternative theoretical framework', Review of Keynesian Economics, 2(3), 312-320.

Pasinetti, L.L. (1962), 'Rate of profit and income distribution in relation to the rate of economic growth', The Review of Economic Studies, 29(4), 267-279.

Reissl, S. (2016), 'Keen on endogenous money and effective demand: a further comment', Review of Keynesian Economics, 4(2), 201-207.

Samuelson, P.A. and F. Modigliani (1966), 'The Pasinetti paradox in neoclassical and more general models', The Review of Economic Studies, 33(4), 269-301.

Sato, K. (1966), 'The neoclassical theorem and distribution of income and wealth', The Review of Economic Studies, 33(4), 331-335. 